\title{
ТЕОРИЯ И ПРАКТИКА НАЗНАЧЕНИЯ НАКАЗАНИЯ В ВИДЕ ЛИШЕНИЯ ПРАВА ЗАНИМАТЬ ОПРЕДЕЛЕННЫЕ ДОЛЖНОСТИ ИЛИ ЗАНИМАТЬСЯ ОПРЕДЕЛЕННОЙ ДЕЯТЕЛЬНОСТЬЮ
}

\begin{abstract}
Аннотация: Авторы рассматривают правоприменительные аспекты назначения наказания в виде лишения права занимать определенные должности или заниматься определенной деятельностью за отдельные виды преступлений.Авторы обращают внимание о необходимости увеличения применения данного наказания в виде лишения права занимать определенные должности или заниматься определенной деятельностью в качестве дополнительного в случае совершения коррупиионного преступления. Отмечается, что в ряде статей Особенной части УК РФ в качестве квалифицирующего обстоятельства указывается на совершение преступления лицом с использованием своего служебного положения, однако в санкииях за них не указывается это наказание. В ходе проведения исследования использовался формально-логический метод, системный анализ, сравнительное правоведение, анкетирование, опрос и статистический метод. Авторами делается вывод о иелесообразности включения в санкции ряда статей Особенной части УК РФ наказание в виде лишения права занимать определенные должности или заниматься определенной деятельностью в качестве обязательного дополнительного наказания. Сформулировано предложение о назначении наказания в виде лишения права занимать определенные должности или заниматься определенной деятельностью наказания путем ограничения сферы действия запрета, в частности путем указания на исполнение конкретных полномочий (на примере медииинских работников).
\end{abstract}

Ключевые слова: Приговор, лишение права, должность, деятельность, должностное лицо, преступление, уголовное наказание, назначение наказания, служебные полномочия, судебная практика.

Abstract: The authors consider the law enforcement aspects of the sentencing in the form of deprivation of the right to hold certain positions or engage in certain activities as a punishment for certain crimes. In the course of the investigation the authors used the formal-logical method, systemic analysis, comparative law, questionnaires, surveys and statistical method. The authors draw attention to the need to increase the application of the penalty of deprivation of the right to occupy certain positions or engage in certain activities as an additional punishment in cases of corruption offenses. It is noted that in a number of articles of the Special Part of the Criminal Code specifies commission of a crime by a person using his official position is an aggravating circumstance, but the penalties do not list the aforementioned method of punishment. The authors substantiate the feasibility of introducing sanctions in a number of articles of the Special Part of the Criminal Code the penalty of deprivation of the right to occupy certain positions or engage in certain activities as a mandatory additional penalty. Proposals are made to appointment of punishment in the form of deprivation of the right to occupy certain positions or engage in certain activities of punishment by restricting the scope of the prohibition, in particular by reference to the performance of specific powers (for example, healthcare workers). Keywords: Imposition of sentence, criminal penalties, crime, officer, work, title, deprivation of rights, sentence, official authority, legal precedent.

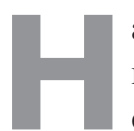

а сегодняшний день проблематика применения наказаний, которые не связаны с лишением свободы, часто обсуждаются учеными, что связано с вопросами их эффективной реализации. Безусловно, для лиц без определенных занятий нецелесообразны как исправительные работы, так и лишение права занимать определенные должности, и даже штраф.

Этот вид предусмотрен в санкциях более чем 80 статей Особенной части уголовного закона, причем в $60 \%$ из них - в качестве дополнительного наказания за общественно опасные деяния, совершенные только при условии использования лицом предоставленных ему в силу занимаемой должности или характера деятельности правомочий.

Срок действия данного наказания определяется судом путем его указания в приговоре и реализуется в ограничении для осужденного свободы выбора вида трудовой деятельности. 
При этом он не может превышать пяти лет при назначении его в качестве основного наказания и трех лет - в качестве дополнительного наказания.

Как мы видим в УК РФ значительно сокращены временные рамки данного наказания, проигнорировав рекомендацию, содержавшуюся в ч. 2 ст. 49 Модельного УК для государств участников СНГ, установить срок лишения соответствующего права в диапазоне от одного года до десяти лет за умышленные преступления и от одного года до пяти лет за неосторожные преступления. [1]

За одно и то же преступление осужденному не может быть назначено одновременно лишение права занимать определенные должности или заниматься определенной деятельностью. [2]

Лишение права занимать определенные должности или заниматься определенной деятельностью выступает как одно из видов дополнительных наказаний, предусмотренных.

Как особенность назначения следует выделять то, что уголовным законом допускается возможность применять указанный вид наказания не только в связи с тем, что оно предусмотрено санкцией конкретной статьи Особенной части УК РФ.

А также это возможно при отсутствии такого предусмотрения. В частности, значимую роль играет то обстоятельство, что по своему характеру совершенное преступление связано с занимаемой осужденным должностью или занятием им же определенной деятельностью. [3]

Рассматриваемый вид наказания выступает как очень эффективное средство противодействия коррупционным преступлениям и обладает очевидным карательным потенциалом, поскольку у осужденного на определенный промежуток времени ограничивается право на труд в определенной сфере деятельности. Это часто приводит к негативным социальным последствиям для осужденного. [4-6]

На учете в Уголовно-исполнительных инспекциях ФСИН России с наказанием в виде лишения права занимать определенные должности или заниматься определенной деятельностью в 2010 году состояло 20481 человек, в 2011 - 22260, 2012 - 21799, 2013 - 21578, 2014 - 19416, 2015 - 12988. [7]

Лишение права занимать определенные должности в качестве дополнительного наказания используется несколько чаще. Однако и в данном случае не совсем понятно, что при- нимается судом во внимание при назначении или, наоборот, отказе от дисквалификации, в первую очередь в отношении лиц, обладающих значительным объемом прав и использующих их вопреки интересам службы.

По результатам проведенного нами исследования в Дальневосточном Федеральном округе в 2013 г. к лишению права занимать определенные должности в качестве дополнительного наказания были осуждены и состояло на учете в УИИ: в Приморском крае 144 человека из них по ст. 290 УК РФ - 5, по ст. 264 УК РФ - 108, по ст. 285-286 УК РФ - 14, по другим ст. УК РФ - 16.

В Сахалинской области 75 человек из них по ст. 290 УК РФ - 5, по ст. 285-286 УК РФ11, по ст. 264 УК РФ - 49, по другим ст. УК РФ - 11 человек.

В Республике Саха (Якутия) 133 человека, из них по ст. 290 УК РФ - 2, по ст. 285-286 УК РФ - 16, по ст. 264 УК РФ - 99, по другим статьям - 16 человек.

В.Н. Кудрявцев считает что, в условиях рыночной экономики следовало бы расширить применение рассматриваемого наказания. Однако эту меру он неразрывно связывает с реформами финансовой, налоговой, административно-кадровой систем и государственного аппарата в целом, которые позволили бы эффективно следить за «движением» осужденных к данному наказанию в «трудовом поле», особенно в частном секторе. [8]

Расширение сферы применения рассматриваемой «дисквалификации» способно существенно уменьшить уровень служебной, в том числе должностной преступности, поскольку чиновники дорожат своим статусом и теми материальными и социальными возможностями, которые им предоставляются в связи с занимаемой должностью. Это подтверждается результатами проведённого нами опроса сотрудников УИИ. Так на вопрос: Эффективно ли данное наказание в борьбе с должностными преступлениями? Из 134 опрошенных сотрудников УИИ 81 ответили утвердительно.

На наш взгляд, принятый в УК РФ порядок регламентации назначения данного вида наказания следует признать правильным. Предусматривая лишение права занимать определенные должности или заниматься определенной деятельностью в соответствующих санкциях норм Особенной части УК РФ в качестве факультативного дополнительного на- 
казания, законодатель тем самым обязывает суд обсуждать в соответствующих случаях вопрос о целесообразности его назначения. В то же время он сверх того предоставляет суду возможность назначить это дополнительное наказание по своему усмотрению.

Е.С. Крылова полагает, что основания назначения лишения права занимать определенные должности или заниматься определенной деятельностью определены в ч. 3 ст. 47 УК РФ, они являются едиными (общими) независимо от того, назначается ли это наказание в качестве основного или дополнительного. [9] Строго говоря, в ч. 3 ст. 47 УК РФ эти основания не отражены. Их можно, на наш взгляд, установить на основе анализа характера тех преступлений, за которые предусмотрено данное наказание в качестве основного или дополнительного.

Оно включено в санкции тех статей Особенной части УК РФ, которые предусматривают ответственность за преступления, которые могут совершаться с использованием занимаемой должности или возможностей, связанных с профессиональной или иной деятельностью. Иначе говоря, оно может назначаться тогда, когда:

a) преступление было связано с занимаемой должностью, профессиональной или иной деятельностью;

б) совершено лицом, которое использовало занимаемую должность либо осуществление профессиональной либо иной деятельности;

в) характер и степень общественной опасности совершенного преступления, личность виновного свидетельствуют о невозможности сохранения за виновным права занятия должности на государственной службе, в органах местного самоуправления или занятия определенной профессиональной или иной деятельностью.

К первой группе могут быть отнесены некоторые преступления против государственной власти, интересов государственной службы и службы в органах местного самоуправления, в сфере экономической деятельности, против интересов службы в коммерческих и иных организациях и др. Ко второй группе относятся некоторые преступления против общественной безопасности и общественного порядка и др.

Третью группу составляют преступления, характер и степень общественной опасности которых, обстоятельства совершения несовместимы с занимаемой лицом должностью или с осуществляемой им профессиональной или иной деятельностью (например, преступления против несовершеннолетних обусловливают необходимость лишения права виновного на педагогическую деятельность в дошкольных учреждениях, школах, средних специальных и высших учебных заведениях). [10]

В связи с этим нельзя не обратить внимание на непоследовательность законодателя в регламентации данного вида наказания. В ряде статей Особенной части УК РФ в качестве квалифицирующего обстоятельства указывается на совершение преступления лицом с использованием своего служебного положения, однако в санкциях за них не указывается это наказание. Законодатель тем самым относит его назначение на усмотрение суда.

С тем чтобы преодолеть данную непоследовательность, следовало бы предусмотреть в санкциях ст. ст. 205.1, 209, 210, 226 и ряда других статей Особенной части УК РФ наказание в виде лишения права занимать определенные должности или заниматься определенной деятельностью в качестве обязательного дополнительного наказания.

Под влиянием устаревших представлений об особенностях применения рассматриваемых наказаний в судебной практике назначения их допускаются ошибки.

Уголовный закон, в том числе ст. 47 УК РФ, не связывает и не ограничивает определение вида должностей, на которые может быть наложен запрет, только должностью, занимаемой лицом во время совершения преступления. Вид должностей, на которые наложен запрет их замещения, судом определен с учетом конкретных обстоятельств преступления, в соответствии с положениями ст. 43 УК РФ, согласно которой наказание применяется, в том числе, в целях предупреждения новых преступлений.

Таким образом, при назначении вида и размера наказания в полной мере учтены положения уголовного закона о его индивидуализации и справедливости. Оснований для смягчения осужденным наказания не имеется.

Однако, по нашему мнению, потенциал данного вида наказания, в полной мере не востребован. Например, анализируя материалы судебной практики по уголовным делам о получении взятки возможно сделать вывод о том, что судом в большинстве случаев при назначении наказания применяется ст. 73 УК РФ. Тем самым, 
постановляется считать назначенное наказание в виде лишения свободы условным. Или ст. 64 УК РФ, руководствуясь которой рассматриваемое дополнительное наказание не назначается.

Мы считаем, что в карательной политике судебных органов подобная тенденция вряд ли соответствует основным принципам уголовного права и соображениям целесообразности, справедливости, экономии мер уголовной репрессии. Безусловно, назначая наказание судом должны быть учтены общие начала и применяться специальные правила. Однако же, рассматривая данный вид наказания на примере медицинских работников, считаем возможным отметить, что определенные вопросы при анализе сложившейся практики применения норм уголовного закона все же возникают. [11]

Вопрос о неприменении к медицинским работникам дополнительного наказания. Так, руководствуясь ст. 64 УК РФ, из общего числа изученных нами дел о получении врачом взятки от пациента в $50 \%$ случаев суд счел возможным не применять дополнительный вид наказания. По ряду дел при кассационном пересмотре дела вышестоящим судом указанный вид наказания исключался из приговора по тем же основаниям.

Мотивация судов при отказе от применения дополнительного наказания чаще всего такова: степень общественной опасности содеянного не высока, совершение преступления впервые, с места работы и по месту жительства - положительные характеристики, малолетние дети, нет отягчающих наказание обстоятельств и др. Данные обстоятельства в своей совокупности, в каждом отдельном случае могут быть признаны как исключительные. Однако, в судебной практике это, скорее, типичная ситуация. В связи, с чем отказ от применения наказания в виде запрета занимать определенную должность или заниматься определенной деятельностью в случае получения медработником взятки, вряд ли можно оправдан.

Конечно, следует принимать во внимание тот факт, что у виновного медицинское образование является основным и единственным. Следовательно, врачебная практика является его основным родом занятий и источником дохода. Запрет заниматься ею ведет к серьезным негативным последствиям для виновного и членов его семьи. Врач, при назначении такого наказания, является по сути безработным и теряет свою квалификацию.
Но, «механический» отказ от применения дополнительного наказания в случае совершения такого коррупционного преступления, как получение взятки, противоречит принципам уголовного права, не способствует достижению целей наказания. В связи с чем, по нашему мнению, следует не просто, ссылаясь на ст. 64 УК РФ, не применять дополнительное наказание в виде запрета заниматься определенной деятельностью, а, напротив, назначать его, но ограничивать при этом сферу действия запрета, в частности путем указания на исполнение конкретных полномочий.

Получение взятки обуславливается осуществлением лицом своих профессиональных обязанностей по оказанию медицинской помощи и должностных полномочий, сопряженных с этим. Например, за совершение следующих действий: получение больничного листа [12], справок о состоянии здоровья, подтверждение либо сокрытие тех или иных медицинских фактов.

Должно быть запрещено выполнение осуществления вышеуказанных служебных полномочий. Поскольку, при осуждении врача речь идет, прежде всего, о злоупотреблении именно предоставленными ему служебными полномочиями. Считаем допустимым не ограничивание лица в плане осуществления профессиональных функций, тем более что практически все осужденные имеют положительные характеристики по месту работы.

Еще один аспект проблемы наказуемости - терминологический. Определяя целесообразность, либо нецелесообразность применения дополнительного наказания, судами, с целью обозначения данного вида профессиональной деятельности, используются разные термины. Так, запрещается заниматься:

а) врачебной деятельностью;

б) медицинской деятельностью;

в) врачебной деятельностью в системе здравоохранения;

г) занимать медицинские должности.

Но чаще всего вид запрещаемой деятельности не определен судами вообще. Часто в приговорах суда встречается законодательная формулировка «определенная деятельность». К сожалению, все это прямо свидетельствует об отсутствии единообразия в практике применения уголовного закона и не способствует выработке единообразной практики применения рассматриваемого вида наказаний. 
Конечно, термин «медицинская деятельность» шире понятия «врачебная деятельность». [13-15] Вместе с тем получение взятки, как правило, не связывается с некачественным оказанием медицинской помощи, лишение права заниматься медицинской практикой вообще вряд ли в рассматриваемых случаях является оправданным.

При назначении этого вида наказания одним из важных моментов является правильная формулировка в приговоре вида должности или иной деятельности, права на занятие которой лишается осужденный. Еще более трех десятков лет назад некоторые авторы указывали, что вопрос о формулировке «занимать определенные должности» оказался сложным применительно к руководителям учреждений и бухгалтерам, осужденным за хищения. Поэтому они предлагали их лишать права занимать должности, связанные с распоряжением, учетом, хранением и иным обслуживанием материальных ценностей. [16]

В резолютивной части обвинительного приговора суд должен конкретизировать, какие именно должности и в каких органах не может занимать осужденный. Суд не вправе обозначать запрет занимать должности таким образом, чтобы он допускал расширительное толкование и позволял тем или иным должностным лицам произвольно ограничивать право гражданина на выбор рода деятельности или профессии в соответствии со ст. 37 Конституции РФ. При этом неважно, занимал он эту должность до осуждения постоянно или временно или но специальному распоряжению.[17]

Те же требования относительно определенности, что и по отношению к занимаемой должности, относятся и к запрету заниматься определенной деятельностью. Род деятельности и ее вид должны быть четко обозначены в приговоре суда - врачебная, педагогическая, частная детективная, охранная, предпринимательская или только торговая деятельность, лишение права управления механическими или иными транспортными средствами, охотой или рыбной ловлей и т.п. [18]

Учитывая вышеизложенное, отметим, что необходимо совершенствовать судебную деятельность, связанную с назначением дополнительного наказания за получение взятки медицинскими работниками.

При разрешении вопросов в отношении медицинского работника о лишении права зани- мать определенную должность или заниматься определенной деятельностью как дополнительном наказании, суды должны исходить из того, что в санкциях ч. ч. 1 и 2 ст. 290 УК РФ этот вид наказания предусматривается в качестве обязательного. В связи с чем, его неназначение может быть связано лишь с наличием исключительных обстоятельств, которые устанавливаются судом.

Несмотря на то, что вопрос об исключительности относится к области судейского усмотрения, законодателем установлены определенные ограничения данного усмотрения. Как исключительные могут определяться обстоятельства, которые связаны с целями и мотивами преступления, ролью виновного, его поведением во время или после совершения преступления и другие обстоятельства, существенно уменьшающие степень его общественной опасности, а равно активное содействие участника группового преступления его раскрытию.

Считаем, что мотивы и цели преступного поведения виновного должны быть лишены низменного характера, а его роль и поведение во время совершения преступления должны быть второстепенными. Что касается поведения виновного после совершения преступления, то оно должно носить характер активных позитивных действий, направленных на уменьшение негативных последствий преступления и скорейшее восстановление нарушенной социальной справедливости. Применительно к фактам получения взятки подобные обстоятельства далеко не всегда имеют место.

Уголовным законодательством судом предоставляется возможность признания исключительными как отдельных смягчающих обстоятельств, так и их совокупность.

При этом в качестве исключительных могут признаваться не только смягчающие обстоятельства, которые законодательно установлены в ст. 61 УК РФ. Но и те, которые не содержатся в данном перечне, но признавались судом таковыми с указанием мотивов принятого решения. Однако принципиально значимым является характер тех или иных обстоятельств, который обусловливает уменьшение степени общественной опасности совершенного преступления.

Исходя из практики речь идет об обстоятельствах, которыми характеризуется непосредственно личность виновного. Учитывать указанные обстоятельства надо, но по иным основаниям. 
Применяя рассматриваемое дополнительное наказание в отношении медицинских работников, при признании их виновными в получении взятки, суды должны исходить из того, что лишение права занимать определенные должности состоит в запрещении занимать должности только на государственной службе или в органах местного самоуправления. Приговор должен содержать конкретный вид таких должностей.

В том случае, если работник учреждения здравоохранения не относится к группе руководителей, а является специалистом, работающим на должностях работников здравоохранения, то в отношении его суд должен назначить дополнительное наказание в виде лишения права заниматься определенной деятельностью, а в приговоре конкретизировать вид такой деятельности.

Например, речь в нем может идти о запрете заниматься врачебной деятельностью, которая связана с выдачей листков больничных листов или выпиской больничных листков и т.п.
По нашему мнению, не обязательно, чтобы лишение права занимать определенные должности или заниматься определенной деятельностью было предусмотрено в соответствующей норме Особенной части УК РФ.

Но в любом случае это наказание можно назначить лишь тогда, когда суд признает невозможным сохранить за виновным право занимать определенные должности или заниматься определенной деятельностью.

Судебная практика, как нам представляется, нуждается в существенной корректировке в сторону увеличения применения данного вида наказания в качестве дополнительного в случае совершения коррупционного преступления, при этом ссылаясь на ст. 64 УК РФ, необходимо, назначать наказание в виде лишения права занимать определенные должности или заниматься определенной деятельностью с ограничением сферы действия запрета, путем указания на исполнение конкретных полномочий.

\section{Библиография:}

1. Информационный бюллетень Межпарламентской ассамблеи государств-участников СНГМПАСНГ. 1995. № 8. С. 119-185.

2. Постановление Пленума Верховного Суда РФ от 22.12.2015 № 58 «О практике назначения судами Российской Федерации уголовного наказания» // «Бюллетень Верховного Суда РФ», № 2, февраль, 2016.

3. Комментарий к Уголовному кодексу Российской Федерации (постатейный) / Г.Н. Борзенков, А.В. Бриллиантов, А.В. Галахова и др.; отв. ред. В.М. Лебедев. 13-е изд., перераб. и доп. М.: Юрайт, 2013. C. 1069.

4. Наумов А.В. Российское уголовное право: Курс лекций: В 3 т. Т. 1. Общая часть. 4-е изд., перераб. и доп. М., 2007. С. 543.

5. Дворецкий М.Ю. Эффективная реализация Постановления Пленума Верховного Суда Российской Федерации от 11 января 2007 года № 2 «О практике назначения судами Российской Федерации уголовного наказания» в оптимизации применения лишения права занимать определенные должности или заниматься определенной деятельностью // Военно-юридический журнал. 2008. № 3. С. 29.

6. Лукашов А. Лишение специального права как вид наказания // Уголовное право. 2009. № 3. С. 31.

7. Отчеты о работе уголовно исполнительных инспекций по форме УИИ-1 за 2010-2015 гг.

8. Кудрявцев В.Н. Стратегии борьбы с преступностью. М., 2003. С. 202.

9. Крылова Е.С. Лишение права занимать определенные должности или заниматься определенной деятельностью как вид уголовного наказания по законодательству России и зарубежных стран: Автореферат дисс. на соиск. уч. степени к.ю.н. - Казань, 2002. С. 18.

10. Капелюшник М.С. Лишение права занимать определенные должности или заниматься определенной деятельностью // Российский следователь. 2006. № 12. С. 25-27.

11. Уголовно-правовое воздействие: монография / Г.А. Есаков, Т.Г. Понятовская, А.И. Рарог и др.; под ред. А.И. Рарога. М.: Проспект, 2012. 288 с.

12. Постановление Президиума Хабаровского краевого суда от 14.03.2011 № 44-у-63/2011 // СПС «Консультант Плюс». Приговор по делу о служебном подлоге и получении должностным лицом взятки за незаконные действия изменен: уточнено назначенное осужденной дополнительное наказание как лишение права заниматься врачебной деятельностью, связанной с осуществлением организационно-распорядительных и хозяйственных функций, в том числе с правом определять временную нетрудоспособность пациентов и выдавать листки нетрудоспособности. Определение Санкт-Петербургского городского суда от 28.09.2010 № 22-6267// СПС «Консультант Плюс».

13. Глашев А.А. Медицинское право: Практическое руководство для юристов и медиков. М., 2004. С. 51.

14. Григонис Э.П., Леонтьев О.В. Ответственность за преступления, совершенные медработниками. СПб., 2008. C. 76.

15. Основы медицинского права России / Под ред. Ю.Д. Сергеева. М., 2007. С. 54 
16. Горелик И.И., Тишкевич И.С. Вопросы уголовного права в практике Верховного Суда БССР. Минск, 1973. С. 162.

17. Рамазанов А.Ж. Наказания, не связанные с лишением свободы (вопросы теории и практики): Учеб. пособие / Под общ. ред. Е.В. Середы. - СПб.: Изд-во юрид. ин-та, 2002. - С 79.

18. Кулешова Н.Н. Дополнительные виды наказаний: уголовно-правовой и уголовно-исполнительный аспекты Дис. ... канд. юрид. наук. Рязань, 2006. С. 143.

19. Багмет А.М. Специальные меры предупреждения коррупции в правоохранительной системе // Союз криминалистов и криминологов. - 2015. - 1. - С. 36 - 39. DOI: 10.7256/2310-8681.2015.1.18591.

\section{References (transliterated):}

1. Naumov A.V. Rossiiskoe ugolovnoe pravo: Kurs lektsii: V 3 t. T. 1. Obshchaya chast'. 4-e izd., pererab. i dop. M., 2007. S. 543.

2. Dvoretskii M.Yu. Effektivnaya realizatsiya Postanovleniya Plenuma Verkhovnogo Suda Rossiiskoi Federatsii ot 11 yanvarya 2007 goda № 2 «O praktike naznacheniya sudami Rossiiskoi Federatsii ugolovnogo nakazaniya» v optimizatsii primeneniya lisheniya prava zanimat' opredelennye dolzhnosti ili zanimat'sya opredelennoi deyatel'nost'yu // Voenno-yuridicheskii zhurnal. 2008. № 3. S. 29.

3. Lukashov A. Lishenie spetsial'nogo prava kak vid nakazaniya // Ugolovnoe pravo. 2009. № 3. S. 31.

4. Kudryavtsev V.N. Strategii bor'by s prestupnost'yu. M., 2003. S. 202.

5. Krylova E.S. Lishenie prava zanimat' opredelennye dolzhnosti ili zanimat'sya opredelennoi deyatel'nost'yu kak vid ugolovnogo nakazaniya po zakonodatel'stvu Rossii i zarubezhnykh stran: Avtoreferat diss. na soisk. uch. stepeni k.yu.n. - Kazan', 2002. S. 18.

6. Kapelyushnik M.S. Lishenie prava zanimat' opredelennye dolzhnosti ili zanimat'sya opredelennoi deyatel'nost'yu // Rossiiskii sledovatel’. 2006. № 12. S. 25-27.

7. Glashev A.A. Meditsinskoe pravo: Prakticheskoe rukovodstvo dlya yuristov i medikov. M., 2004. S. 51.

8. Grigonis E.P., Leont'ev O.V. Otvetstvennost' za prestupleniya, sovershennye medrabotnikami. SPb., 2008 . S. 76.

9. Gorelik I.I., Tishkevich I.S. Voprosy ugolovnogo prava v praktike Verkhovnogo Suda BSSR. Minsk, 1973. S. 162.

10. Ramazanov A.Zh. Nakazaniya, ne svyazannye s lisheniem svobody (voprosy teorii i praktiki): Ucheb. posobie / Pod obshch. red. E.V. Seredy. - SPb.: Izd-vo yurid. in-ta, 2002. - S 79.

11. Kuleshova N.N. Dopolnitel'nye vidy nakazanii: ugolovno-pravovoi i ugolovno-ispolnitel'nyi aspekty Dis. ... kand. yurid. nauk. Ryazan', 2006. S. 143.

12. Bagmet A.M. Spetsial'nye mery preduprezhdeniya korruptsii v pravookhranitel'noi sisteme // Soyuz kriminalistov i kriminologov. - 2015. - 1. - C. 36 - 39. DOI: 10.7256/2310-8681.2015.1.18591. 